\title{
Renal Transplantation in Identical Twins
}

\author{
T. E. Starzl, M.D., R. S. Brittain, M.D., O. G. Stonnington, M.D., W. R. Coppinger, M.D., and \\ W. R. Waddell, M.D. \\ Markle Scholar and Associate Professor of Surgery (Dr. Starzl); Instructor in Surgery (Dr. \\ Brittain); Associate Professor of Surgery (Dr. Stonnington); Clinical Instructor in Surgery (Dr. \\ Coppinger); Professor of Surgery (Dr. Waddell). Departments of Medicine and Surgery, University \\ of Colorado Medical Center, The Denver Veterans Administration Hospital, and the Denver Clinic
}

Since 1954, renal transplantation from one identical twin to another has been reported in 25 cases, $1,6-9,12,15,18,22$ of which 18 have been done by Murray and his associates ${ }^{15}$ in Boston. Inasmuch as such twins develop from the same fertilized ovum, their tissues are genetically identical and consequently mutually acceptable for homografting. ${ }^{5,13}$ The problems encountered with tissue transplantation under these circumstances are essentially technical and concern details of procurement, transfer, and revascularization of the kidney.

The present report is of a renal transplantation performed in March, 1962. The kidney was donated by a healthy 27 -year-old man to his identical twin brother who suffered from terminal glomerulonephritis. In caring for these patients, some variations were evolved from the operative methods previously standardized by Murray, Merrill, and Harrison, ${ }^{13,18}$ involving not only the removal but the preservation and reimplantation of the kidney. In addition, a syndrome of postoperative microscopic hematuria occurred in the recipient patient which, although seen in previous cases, ${ }^{16}$ has not been described in the literature.

\section{Report of a Case}

A 27-year-old white male was referred to the Denver Veterans Administration Hospital on Feb. 6, 1962, in hypertensive crisis. In 1955 the patient had been medically evaluated because of bilateral costovertebral angle pain. There was no antecedent illness. A diagnosis of acute and chronic glomerulonephritis was made on the basis of albuminuria, hematuria, and mild hypertension. The symptoms regressed promptly, and he had no further complaints until 1959. However, a routine urinalysis performed in 1958 had revealed proteinuria, hematuria, and hyaline, and granular casts.

In 1959 the patient first noticed intermittent ankle edema and easy fatigability. In September of 1960, he was first seen by Dr. Phillip Clarke of Denver, Colorado. His blood pressure was $160 / 104 \mathrm{~mm}$. Hg. Urine findings were unchanged. Blood urea nitrogen was $20 \mathrm{mg} . \%$, creatinine $2.0 \mathrm{mg} . \%$, total protein $5.5 \mathrm{gm} . \%$ with $2.9 \mathrm{gm}$. of albumin. He was placed on a low salt, low protein diet and treated with chlorothiazide (Diuril) and potassium chloride. On this regimen he became relatively asymptomatic, but by November of 1961, the plasma creatinine had risen to $4.5 \mathrm{mg} . \%$, the blood urea nitrogen to $64 \mathrm{mg} . \%$, and the blood pressure to $210 / 140 \mathrm{~mm}$. Hg. In January of 1962, the patient developed headaches, blurring of vision, increased irritability, and intermittent diarrhea.

Copyright 1963, by American Medical Association

Thomas E. Starzl, M.D., Associate Professor of Surgery, University of Colorado Medical Center, 4200 E. 9th Ave., Denver 20, Colo.

Addendum: The patient continues to be in good health with excellent renal function, 10 months after renal transplantation. 
On physical examination, his blood pressure was found to be $220 / 145 \mathrm{~mm}$. Hg, pulse 80 , respirations 26 per minute, temperature $37.5 \mathrm{C}$. He was well oriented. The conjunctivas were pale. On funduscopic examination there was bilateral arterial spasm, a few flame hemorrhages, and early papilledema. There was slight pretibial edema.

Laboratory studies revealed a hematocrit of $36 \%$, hemoglobin $12.4 \mathrm{gm} . \%$, white blood count 12,400, with 92 neutrophils. Sedimentation rate was 38 . Blood urea nitrogen was $39 \mathrm{mg} . \%$, and creatinine $4.6 \mathrm{mg} . \%$. Total protein was $5.25 \mathrm{gm} . \%$ with $2.75 \mathrm{gm}$. albumin. Serum electrolytes were: $\mathrm{CO}_{2}, 17 \mathrm{mEq}$. per liter, chlorides $115 \mathrm{mEq}$. per liter, sodium $144 \mathrm{mEq}$. per liter, potassium $5.0 \mathrm{mEq}$. per liter, calcium $9.5 \mathrm{mg} . \%$, and phosphorus $5.2 \mathrm{mg} . \%$. Urine cultures were negative. Urinary protein for 24 hours was $4.3 \mathrm{gm}$. Creatinine clearance was 21.6 and $24.5 \mathrm{cc}$. per minute. ASO titre was less than 125 Todd units. Urinary sodium was $39 \mathrm{mEq}$. per liter and potassium $22 \mathrm{mEq}$. per liter.

The patient was treated with phenobarbital, hydralazine (Apresoline), chlorothiazide, and reserpine, with a prompt drop in blood pressure (Fig. 1). The eyeground changes showed slow but definite resolution over the next few days. Urinary output remained relatively constant at about 2,200 cc. daily (Fig. 1). Despite control of the patient's blood pressure, clinical deterioration was rapid. By March 23 the BUN had risen to $104 \mathrm{mg} . \%$, and the creatinine to $5.3 \mathrm{mg} . \%$ (Fig. 2). During this period, his hematocrit had failed to $29 \%$. Transplantation was carried out on March 27, 1962.

\section{Studies on the Donor Patient}

Having learned of the presence of a twin brother, Dr. Phillip Clarke had initiated studies as early as September, 1961, to establish twin identity. Upon superficial examination, the donor patient did not appear to be an identical twin, largely because of an orthopedic deformity which had resulted in rather severe thoracolumbar scoliosis and a reduction in his height. A pathologic record of the placenta from their delivery was unobtainable. Blood-group matchings were obtained (Table) and were identical for the groups studied. Mutual transfer of split thickness skin grafts was carried out between the patients' thighs on Nov. 11, 1961. Neither graft was rejected, and biopsy of both grafts on Feb. 19, 1962 revealed no evidence of rejection.

An intravenous pyelogram in the donor patient was normal. BUN was $15 \mathrm{mg} . \%$, and creatinine was $1.1 \mathrm{mg} . \%$. A retrograde aortogram revealed good visualization of a single renal artery to each kidney.

\section{Operation on Donor Patient}

The operation was performed through a left flank incision beneath the 12th rib on March 27, 1962 , under general body hypothermia of $32 \mathrm{C}$. The scoliosis which projected the left kidney into the wound insured good exposure. After opening Gerota's fascia, the renal capsule was freed, taking care to ligate all vessels. The ureter was mobilized inferiorly over the pelvic brim, preserving the surrounding areolar tissue. A triangular section of areolar and fatty tissue between the ureteral pelvic junction and the renal vessels was left with the specimen to insure proper vascularization of the upper ureter and pelvis (Fig. 3). The renal artery and renal vein were then cleaned off back to their respective junctions with the aorta and the inferior vena cava. The ureter was then transected in the pelvis, leaving the kidney attached only by its vascular pedicle. Ten minutes before the nephrectomy was completed, the patient was given $2 \mathrm{mg}$. per kilogram heparin systemically. Upon subsequent command from the recipient room, the renal artery and vein were clamped at their proximal end, and the vessels were transected. The kidney was removed to the recipient operating room, and the stumps of the vessels in the donor patient were closed with continuous No. 00000 
arterial silk. Immediately after the nephrectomy had been completed, the donor patient was given a neutralizing dose of hexadimethrine bromide (Polybrene). The wound was closed in layers without drainage, and rewarming carried out.

\section{Operation on Recipient Patient}

In the adjacent operating room, the graft site was prepared in the right iliac fossa of the recipient patient, employing a transverse lower abdominal incision which was extended into the right flank. A retroperitoneal plane of dissection was used. The common, external, and internal iliac artery, and vein were mobilized. At this time it was determined that the internal iliac (hypogastric) artery was partially occluded by extensive atheromata, and it was decided at this time to implant the renal artery into the side of the common iliac artery. The precise location of the proposed arterial and venous anastomoses was selected, and instructions were then passed to the donor operating room to remove and bring in the kidney.

The donor patient's left kidney was then placed in the right iliac fossa so that its former posterior surface was directed anteriorly, thus reversing the relationships of the renal pedicle (Fig. 4). An end-to-side renal vein to common iliac vein anastomosis was performed using continuous No. 000000 arterial silk (Fig. 4). The end of the renal artery was next anastomosed to the side of the common iliac artery with a similar technique. The occluding vascular clamps were then released, and prompt revascularization of the kidney was noted. The total ischemic period of the renal graft was 36 minutes.

Two hundred forty mg. per kilogram of mannitol was administered intravenously at this time, and eight minutes later copious urine flow was noted. Ureterocystostomy was performed using the technique of Stevens and Marshall ${ }^{21}$ as modified by Paquin, ${ }^{20}$ in which a submucosal tunnel is combined with ureteral tip eversion (Fig. 5). The ureterocystostomy was placed as far posteriorly as possible in order to minimize movement of the anastomosis with bladder filling. The graft was fixed in the right iliac fossa with capsular sutures. The right kidney was then removed through the same retroperitoneal incision without difficulty. Bladder drainage was provided with a urethral catheter. Two drains were left in the retroperitoneal space. A transfusion of $500 \mathrm{cc}$. blood was given.

Six days later, on March 2, 1962, a left nephrectomy was performed through an anterior retroperitoneal approach.

\section{Postoperative Course}

Both patients recovered promptly from their surgical procedures. The donor twin was discharged from the hospital 10 days after operation.

For the first 3 days after transplantation, the recipient patient had a marked diuresis, averaging 6,100 cc. per day (Fig. 1). Urinary electrolytes during this period were: sodium 80 to $100 \mathrm{mEq}$. per liter, potassium 10 to $11 \mathrm{mEq}$. per liter, chlorides 45 to $55 \mathrm{mEq}$. per liter. The urinary concentrations of creatinine and urea during the diuresis were $38 \mathrm{mg} / 100 \mathrm{cc}$ and $490 \mathrm{mg} / 100 \mathrm{cc}$ respectively. By the third postoperative day, the urinary electrolytes were: sodium $11 \mathrm{mEq}$. per liter, potassium $32 \mathrm{mEq}$. per liter, and chlorides $16 \mathrm{mEq}$. per liter, at which time the plasma concentrations of urea and creatinine were within normal limits (Fig. 2). Subsequently in this patient's course the urinary concentration of electrolytes fluctuated widely. Fluid therapy during the diuresis was based on six hourly determinations of urinary volume and composition. Initially fluid and electrolytes were replaced quantitatively. The cessation of diuresis corresponded to the period of urinary sodium conservation, starting on the third day, and fluid and electrolyte replacement was reduced accordingly. Diet was resumed on the fourth postoperative day. 
There was no significant change in blood pressure following the transplantation, but beginning approximately one week after the left nephrectomy, the recipient patient's blood pressure dropped to within normal limits (Fig. 1), and has remained at a normal level for the ensuing six months.

The clinical course of the recipient patient after both operations was quite benign except for a transient fever of $103 \mathrm{~F}$ immediately after removal of his urethral catheter on the 12th day. Urinary culture at this time revealed a light growth of Pseudomonas aeruginosa. He received a five day course of streptomycin ( $1 \frac{1}{2} \mathrm{gm}$. per day), and multiple cultures were subsequently negative. He was discharged to the medical service four weeks after transplantation and right nephrectomy, and three weeks after the left nephrectomy. He was discharged from the hospital on June 14, 1962, and has since remarried. He holds a full-time job as an accountant.

Repeated urinary function studies have been done since operation. On April 5, 1962, nine days after transplantation and three days after removal of the remaining kidney, the one hour phenolsulfonphthalien excretion was $35 \%$, and the creatinine clearance $84 \mathrm{cc}$. per minute. Multiple creatinine clearance determinations in the hospital (Fig. 2) and after discharge showed a slow increase, so that six months postoperatively it was $100 \mathrm{cc}$. per minute. Renal blood flow, and tubular and glomerular function will be the subject of a separate report, ${ }^{11}$ but these measures were higher than normal for a single kidney.

The only disturbing postoperative feature was the presence of microscopic hematuria which was first noted immediately after operation and which has continued until the present time. The red blood cell count in a 24 hour specimen ranged from 2 to 100 times that normally found. The hematuria disappeared or was greatly reduced when the patient was confined to bed. The hematuria, in addition to a low serum complement level, raised suspicion that the graft was developing glomerulonephritis. The patient was given a course of cortisone from May to August, 1962. The hematuria was uninfluenced, and the cortisone therefore withdrawn.

\section{Comment}

A critical aspect of the preoperative evaluation for renal transplantation is the establishment of true identity between the donor and recipient twins. Although there have been reports of prolonged survival of kidney grafts in nonidentical twins, the recipient patient requires irradiation or cytotoxic drugs to suppress the immune mechanism, and with all present techniques of: host conditioning the results are indifferent. ${ }^{10,17}$ In the patients described here, the difference in appearance, secondary to an old orthojpedic deformity in the donor, made it at first difficult to believe that they were identical twins. Identity was proved by the demonstration that 18 blood groups were the same in both patients (Table), and by the failure of rejection of the cross-skin grafts.

Another problem was the selection of the proper kidney for grafting. Scoliosis in the donor caused the left kidney to be displaced into an exposed and superficial position, potentially subject to future trauma. For this reason, it was thought that use of the left kidney was mandatory. Aortography, performed one month before operation, showed that this kidney was supplied by a single artery of ample length and diameter. It is possible that aortography should be more commonly performed in the preoperative evaluation of the donor patients. In the first 12 cases of this type, information is available concerning the anatomy of the arterial supply. 6,7,9,12,18,22 Two or more renal arteries to the donor kidney were found in four of the 12 cases. ${ }^{18,22}$ If this information were available in advance, technical management could be planned at leisure. In addition, provision could be made for protection of the graft from 
ischemia by cooling or other means, since the time for reestablishment of the vascular supply is inevitably increased under these circumstances.

In planning the operation there was considerable concern about the potential adverse effects of the ischemic period during transfer and revascularization of the graft. Despite the experience in previous cases of renal grafts that devascularization can be tolerated for as long as 90 minutes with eventual satisfactory restoration of function, the most rapid recovery in terms of immediate diuresis and restoration of normal blood chemistries has been in cases of the briefest ischemia. The patients of $\mathrm{Cohn}^{6}$ and Hume and Schilling, ${ }^{9}$ in whom ischemia was limited to 22 and 45 minutes respectively, had complete clearing of azotemia in three days. When the devascularized period had exceeded 45 minutes, azotemia has usually persisted for weeks or months. Diuresis from the transplant may be delayed. ${ }^{18,22}$ In Dosseter's well-studied case, in which revascularization required 58 minutes, there was serious depression of graft function which began on the third postoperative day and lasted for several weeks. It was felt by the authors that this was a delayed result of ischemia. Of particular interest is the difference in late graft function in the patient reported by $\mathrm{Bricker}^{4}$ as compared to the patient studied by Guin and his associates. ${ }^{9}$ In the former case, in which the graft was devascularized for 89 minutes, there were abnormalities in sodium excretion one year after surgery following extracellular fluid volume alterations. In the latter case, in which the graft was devascularized for 45 minutes, sodium excretion and all other functions were entirely normal.

In the present case it was hoped to provide maximum security for the renal graft in two ways. The first of these was to insure maximum speed of reconstitution of the vascular supply. This was achieved in a period of 36 minutes. Additional protection was obtained by subjecting the donor patient to moderate hypothermia, since it has been shown by Owens, ${ }^{19}$ Bogardus, ${ }^{3}$ and many subsequent investigators that this adjuvant increases tolerance to ischemia. Although hypothermia has not been employed in other cases of renal homotransplantation between identical twins, it has been described by Hamburger and his associates ${ }^{10}$ in homografts between nonidentical twins.

In addition, the donor was given $2 \mathrm{mg}$. per kilogram of heparin systemically a few minutes before the kidney was removed. This measure, designed to prevent clotting within the organ, was previously used by Cohn and his associates in a clinical case, ${ }^{6}$ administering a neutralizing dose of hexadimethrine immediately after removal of the kidney. In experimental animals it has been demonstrated by Mims ${ }^{14}$ that the effective renal blood flow returns much more rapidly when the graft has been heparinized.

In dissecting the kidney in the donor patient, special care was directed to the preservation of the ureteropelvic blood supply. It is well known that long segments of ureter can be mobilized without adverse effects, providing that the adventitia is retained. Prior to surgery, it was determined by cadaver dissections that the upper ureter was constantly supplied by numerous small vessels which originated from the renal artery and descended in the fatty areolar tissue located in the triangular space between the renal vessels and the upper ureter (Fig. 3). This region was therefore carefully preserved, and the fatty and areolar tissue was transplanted along with the kidney.

In all previous cases of transplantation in identical twins, the principal arterial blood supply has been restored by an end-to-end renal artery-hypogastric artery anastomosis. In Creech's case, the hypogastric artery was the site of severe atherosclerosis, and a preliminary endarterectomy was necessary. ${ }^{12}$ In our case, multiple atheromata made the hypogastric artery unsuitable for use. Consequently, an alternative procedure was employed using an end-to-side anastomosis between the renal and the common iliac arteries. Mims ${ }^{14}$ has 
studied the relative effectiveness of end-to-side versus end-to-end anastomosis in renal transplants in dogs. These authors found that with an end-to-side anastomosis, the degree of compensatory hyperplasia as well as the renal plasma flow were somewhat reduced. However, in our case there appeared to be no adverse functional effects from this variation in technique. Postoperative renal plasma flow and other functional tests were quite satisfactory, both immediately and for as long as six months postoperatively.

The method of implantation of the ureter into the bladder would appear to be important in terms of long-term success, since several of the previously reported cases have had persistent urinary tract infections after operation. The method of implantation should provide free urinary drainage, and prevent reflux. In the presently reported case, the method of Stevens and Marshall ${ }^{21}$ was employed as modified by Paquin. ${ }^{20}$ A submucosal tunnel was fashioned, through which the ureter was brought. In addition, the tip of the ureter was folded back to form a nipple projecting into the interior of the bladder (Fig. 5). In our case urinary drainage was demonstrated to be unimpeded, and there was no pyelographic evidence of regurgitation.

One of the most dreaded late complications of renal transplantation, particularly in patients whose initial disease was glomerulonephritis, has been recurrence of the disease in the transplanted kidney. ${ }^{18}$ When this has occurred, the recurrent glomerulonephritis has run an accelerated course. There is suggestive evidence that removal of the diseased kidneys may help contravert this complication. ${ }^{18}$ The timing for removal of the recipient patient's own kidneys has varied from seven days to six months. In our case, the recipient's right kidney was removed through the same retroperitoneal incision used for the transplantation. From a technical point of view, this was easily accomplished. The second or left kidney of the recipient patient was removed six days later through a separate incision.

It has been noted on numerous occasions that a successful renal transplant provides a copious immediate diuresis. A large part of this effect is probably attributable to the osmotic diuretic effect of the elevated plasma urea. In the present case, mannitol was given at the time of transplantation in order to promote an immediate diuresis. Whether this form of therapy is advisable is open to question in view of recent studies which suggest that mannitol may complicate the postoperative course by causing sodium loss. ${ }^{2}$ In addition, it is doubtful that mannitol acts in a manner different from that of endogenous urea. Whether mannitol is or is not given, it is clear that a precise record of not only water but electrolyte losses must be kept in order to treat rapid and potentially lethal fluid or electrolyte depletion effectively.

The recovery of the recipient patient from the two operative procedures was surprisingly benign in view of his critically ill and feeble condition. One postoperative finding which occasioned considerable anxiety was the early development and subsequent persistence of microscopic hematuria. This was noted in the immediate postoperative period and continued for many months. A striking feature of the hematuria was its almost complete disappearance when the patient was confined to bed rest. This complication has not been previously described in the literature, but it has been noticed by Murray. ${ }^{16}$ The exact mechanism of the persistent hematuria is not clear, but is it influenced by position. Further information on this postoperative complication would appear to be important, particularly in differentiating it from the hematuria which might be anticipated if recurrent glomerulonephritis supervened, inasmuch as the therapy would be quite different. 


\section{Summary}

A successful case of renal transplantation from one identical twin to another has been presented. The variations from previously employed techniques have been discussed.

\section{Acknowledgments}

Aided by Grants A-3176 and A-6283 from the United States Public Health Service.

Grateful acknowledgment is made to the large group of physicians and surgeons who participated in the care of the patients before, during and after operation. These included Dr. Gilbert Hermann, Dr. Phillip Clarke, Dr. Richard Sanders, Dr.Donald Dickhaus, Dr. Joel Holmes, Dr. Martin Hutt, Dr. Gordon Meiklejohn, Dr. Frank Bland, and Dr. William Rettberg.

\section{References}

1. Allbritten, FF. Personal communication to the author. Sept 7. 1962

2. Boba A, Gainor J, Powers SR. Mannitol Influence on Water and Electrolyte Excretion. Surgery. 1962; 52:188. [PubMed: 13870281]

3. Bogardus GM, Schlosser RJ. The Influence of Temperature upon Ischemic Renal Damage. Surgery. 1956; 39:970. [PubMed: 13324611]

4. Bricker NS, Guild WR, Reardan JB, Merrill JP. Functional Capacity of a Denervated Homotransplanted Kidney in an Identical Twin with Parallel Observations in the Donor. J Clin Invest. 1956; 35:1364. [PubMed: 13385335]

5. Brown JB. Homografting of Skin: With Report of Success in Identical Twins. Surgery. 1937; 1:558.

6. Cohn R, Oberhelman H Jr, Young J, Holman HA. A Successful Case of Homotransplantation of the Kidney Between Identical Twins. Amer J Surg. 1961; 102:344. [PubMed: 13694480]

7. Dossetor JB, MacKinnon KJ, Luke JC, Morgan RO, Beck JC. Renal Transplantation Between Identical Twins. Lancet. 1960; 2:572. [PubMed: 13817747]

8. Dunphy, JE. Discussion of Cohn ${ }^{6}$.

9. Guin HE, Unger A, Hume D, Schilling J. Human Renal Transplantation. J Lab Clin Med. 1960; $56: 1$.

10. Hamburger J, Vaysse J, Crosnier J, Auvert J, Lalanne CM, Hopper J Jr. Renal Homotransplantation in Man After Radiation of the Recipient: Experience with 6 Cases Since 1959. Amer J Med. 1962; 32:854. [PubMed: 13904073]

11. Hutt, MP.; Holmes, JH.; Clarke, PJ.; Dickhaus, DW. Unpublished data.

12. Menville JG, Schlegel JU, Pratt AM II, Creech O Jr. Human Kidney Transplantation in Identical Twins. J Urol. 1961; 85:233. [PubMed: 13769506]

13. Merrill JP, Murray JE, Harrison JH, Guild WR. Successful Homotransplantation of the Human Kidney Between Identical Twins. J A M A. 1956; 160:277. [PubMed: 13278189]

14. Mims MM. Hemodynamics of Renal Transplantation. J Urol. 1961; 86:493. [PubMed: 14474254]

15. Murray, JE. Personal communication to the author. Sept 13.1962

16. Murray, JE. Personal communication to the author. April. 1962

17. Murray JE, Merrill JP, Dammin GJ, Dealy JB, Alexandre GW, Harrison JH. Kidney Transplantation in Modified Recipients. Ann Surg. 1962; 156:337. [PubMed: 14477464]

18. Murray JE, Merrill JP, Harrison JH. Kidney Transplantation Between 7 Pairs of Identical Twins. Ann Surg. 1958; 148:343. [PubMed: 13571912]

19. Owens JC, Prevedel AE, Swan H. Prolonged Occlusion of the Thoracic Aorta During Hypothermia. A M A Arch Surg. 1955; 70:95. [PubMed: 13217608]

20. Paquin AJ. Ureterovesical Anastomosis: The Description and Evaluation of a Technique. J Urol. 1959; 82:573. [PubMed: 14430329]

21. Stevens AR, Marshall VF. Reimplantation of the Ureter into the Bladder. Surg Gynec Obstet. 1943; 77:585. 
22. Woodruff MF, Robson JS, Ross JA, Nolan B, Lambie AT. Transplantation of a Kidney from an Identical Twin. Lancet. 1961; 1:1245. [PubMed: 13786554] 


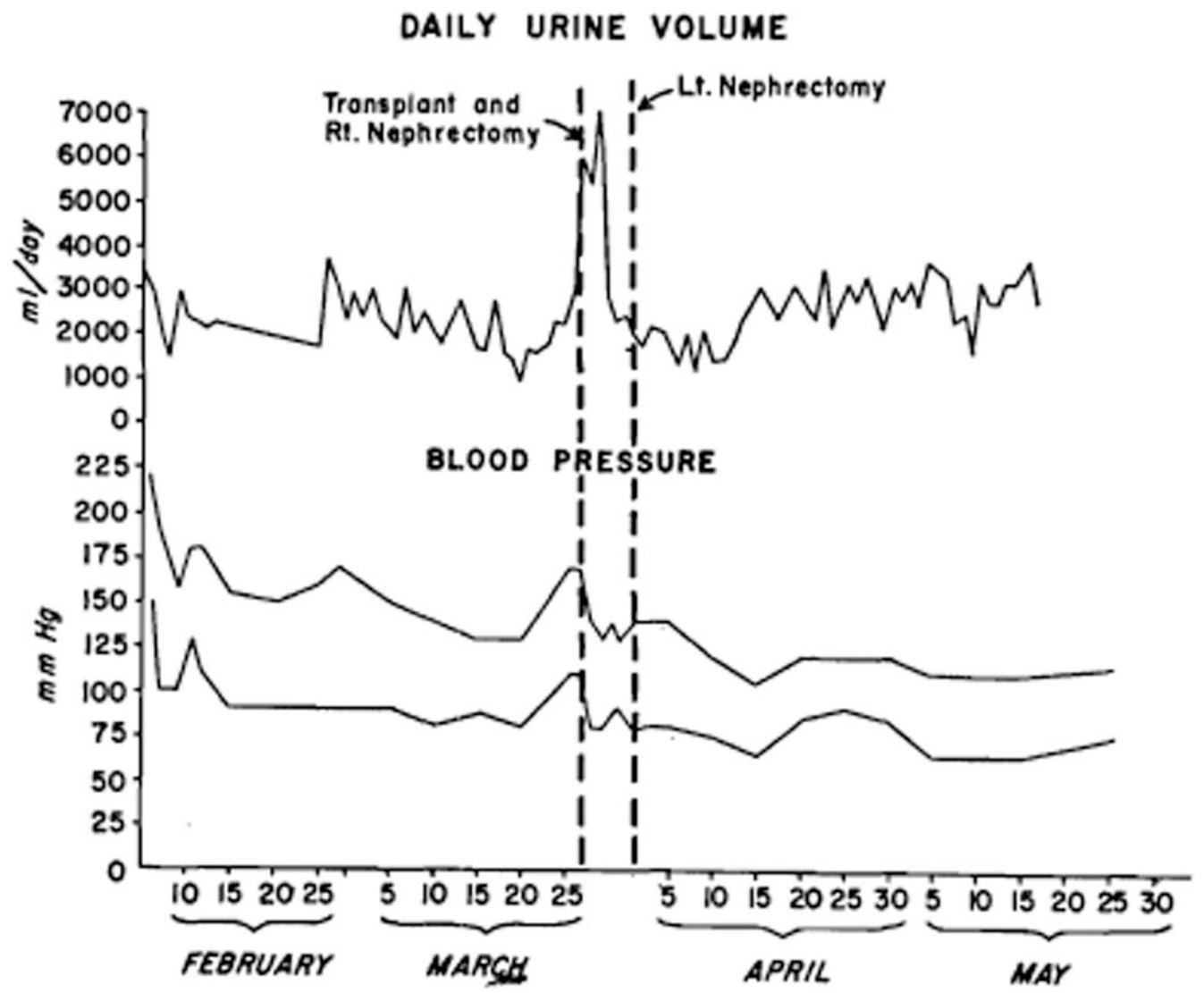

Fig. 1.

Blood pressure and daily urinary volume for the 2 months preceding and the 2 months following renal transplantation. 
CREATININE CLEARANCE

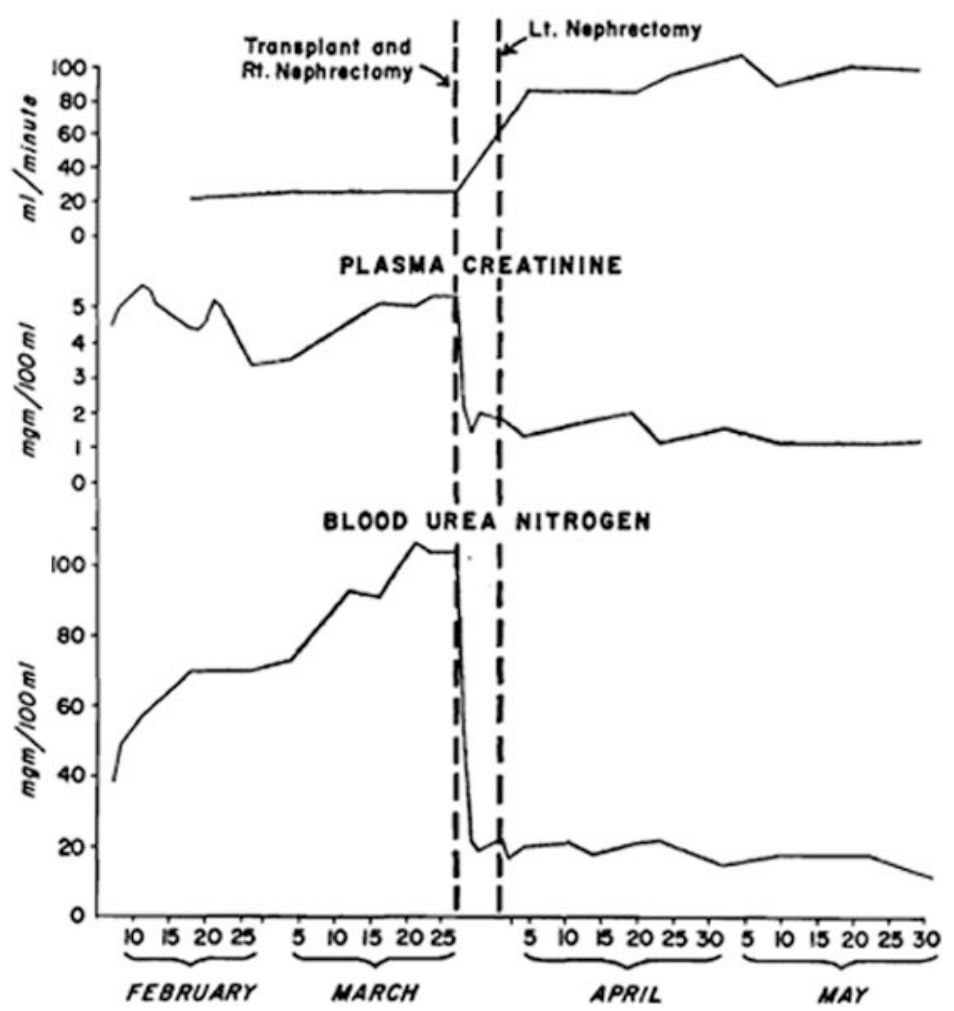

Fig. 2.

Creatinine clearance, plasma creatinine, and blood urea nitrogen before and after renal transplantation. 


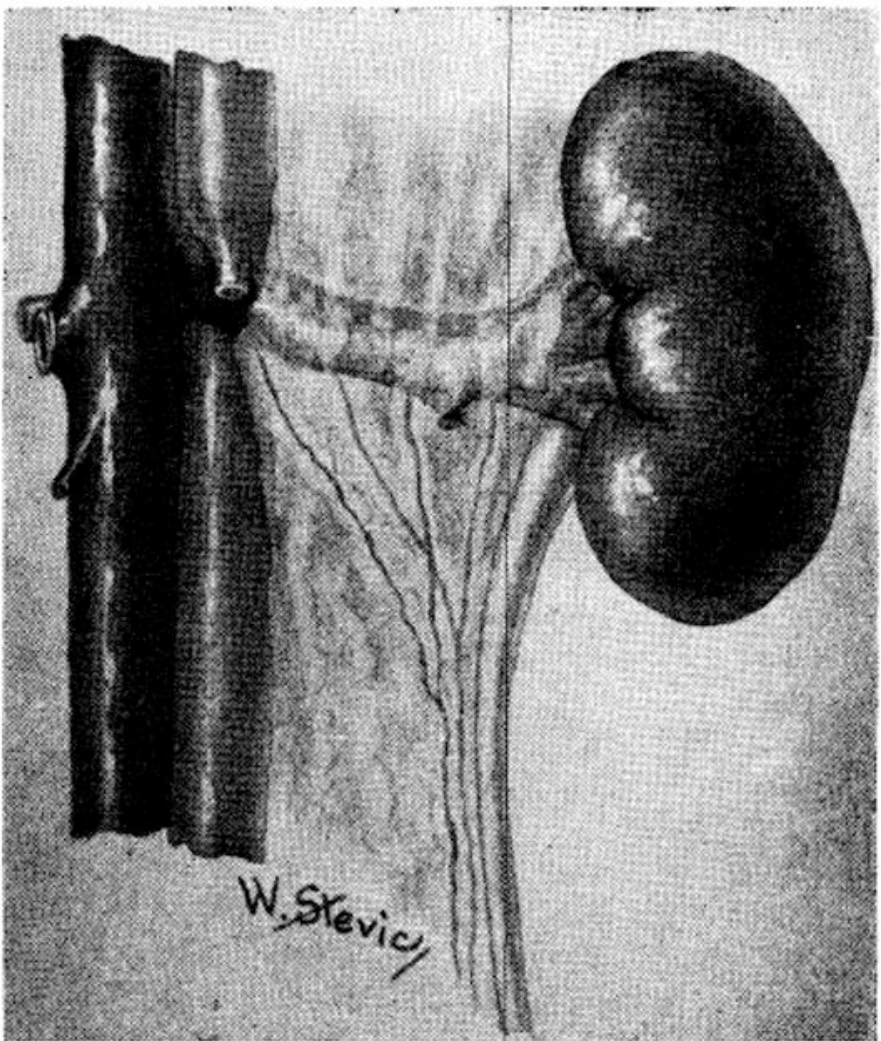

Fig. 3.

Diagram of donor kidney showing prevention of pelvic and upper ureteral blood supply. 


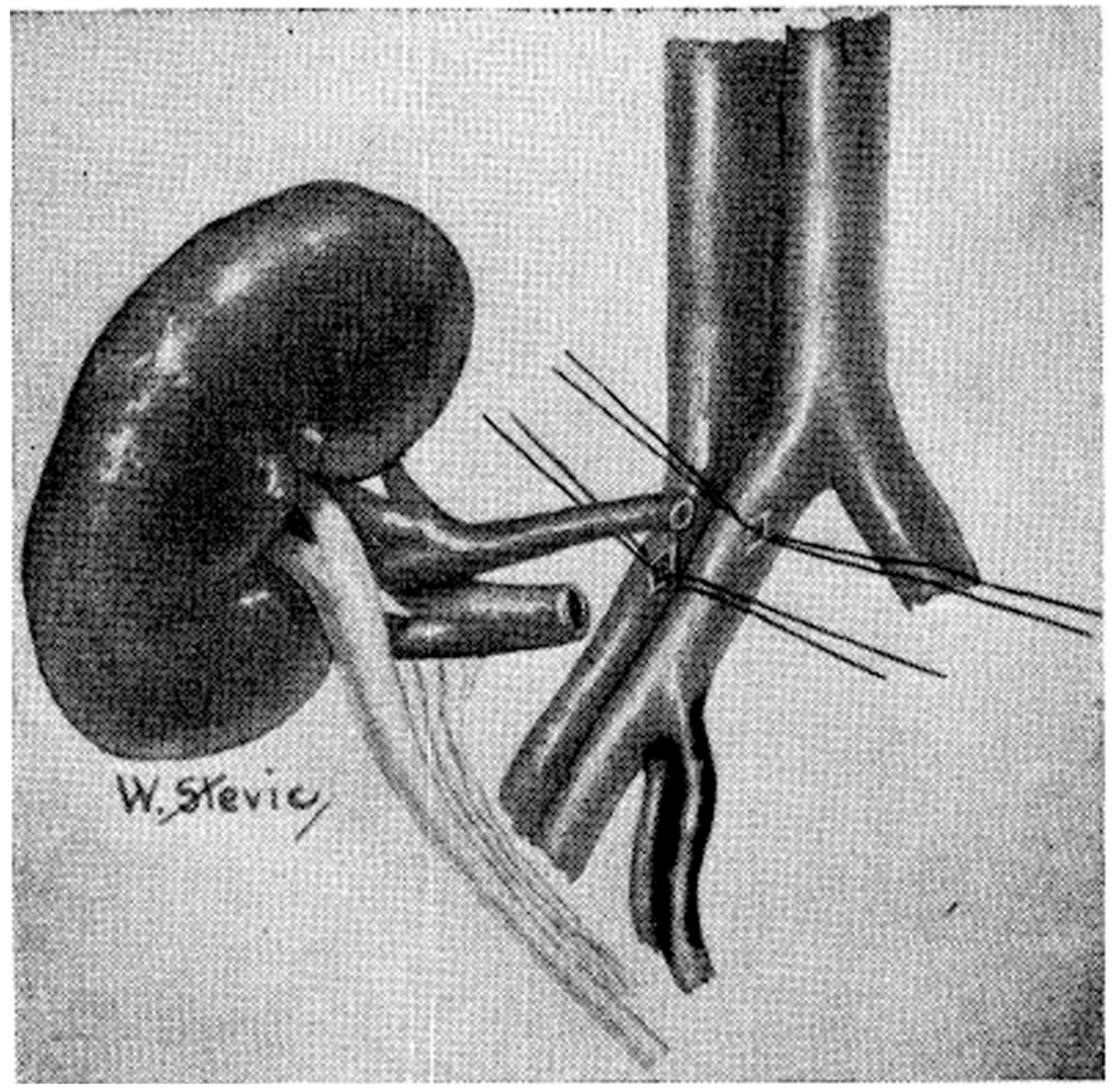

Fig. 4.

Donor kidney in recipient site. Note the reversed relationship of the pedicle structures in the graft bed. End-to-side anastomoses were performed with both artery and vein. 


\section{URETEROVESICLE ANASTOMOSIS}

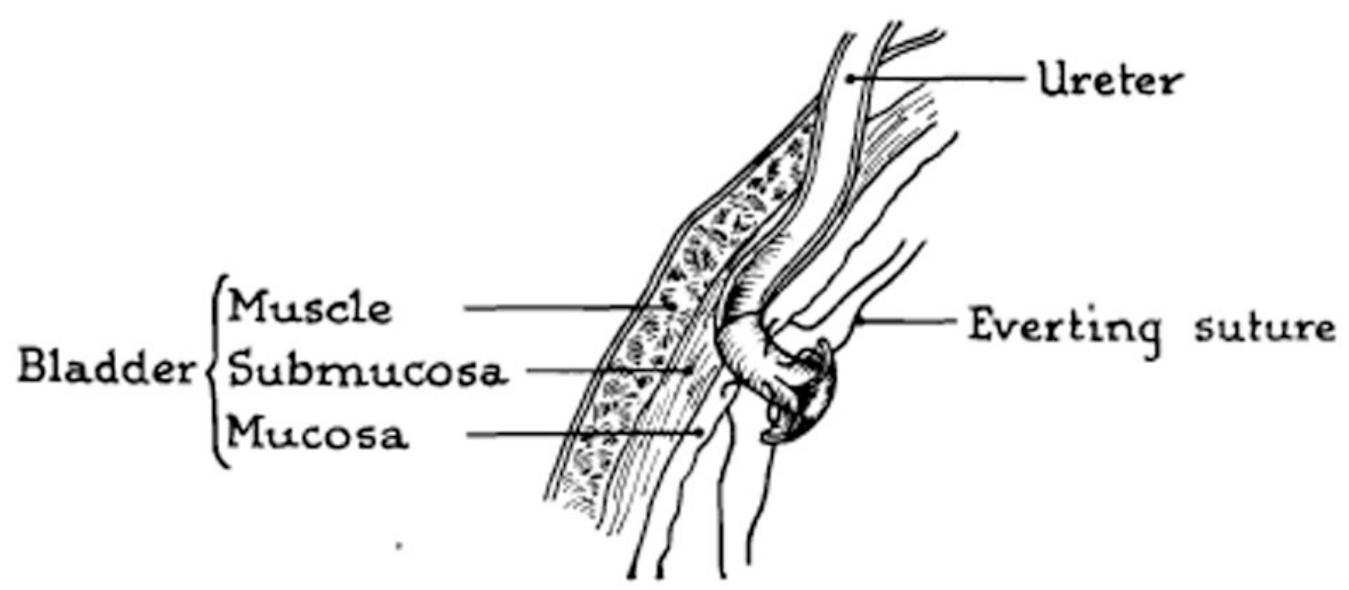

Fig. 5.

Method of ureterocystostomy using method of Paquin, ${ }^{20}$ employing combination of submucosal tunnel and ureteral nipple. 


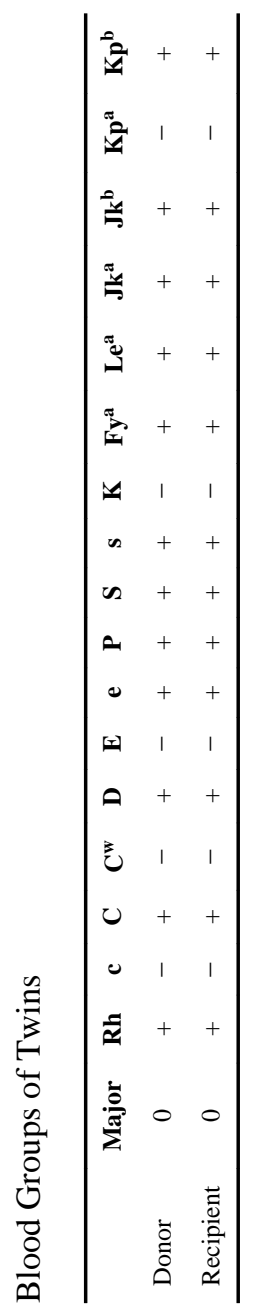

